- An in-depth analysis of dentists' knowledge, attitude and practices towards patients carrying blood-borne viruses are described.

- This paper explores four major themes.

- There are important implications for the treatment of HIV+ patients in NHS dentistry.

\title{
A qualitative exploration of dental practitioners' knowledge, attitudes and practices towards HIV+ and patients with other 'high risk' groups
}

\author{
M. L. Crossley ${ }^{1}$
}

This paper expands upon a previous quantitative study which measured dentists' knowledge, attitudes and practices towards patients carrying blood-borne viruses in order to identify potential barriers to the provision of adequate dental treatment. Although some useful findings were obtained in that study, it was suggested that further qualitative work needed to be conducted in order to provide the opportunity for dental practitioners' to expand, reflect and justify their opinions and beliefs in more detail. The aim of this study is to present the results of such a qualitative investigation.

\section{INTRODUCTION}

It has been suggested in recent years that dental care providers have an ethical and legal obligation to treat HIV-infected patients. ${ }^{1}$ Despite recent recommendations by dental associations, however, there is some evidence to suggest that many dentists remain reluctant to treat patients with HIV/AIDS and other groups at high risk from blood-borne pathogens. ${ }^{2}$ Previous studies in both the $\mathrm{UK}^{3}$ and $\mathrm{US}^{4,5}$ have examined dentists' knowledge, attitudes and behaviours in order to assess which factors may be influential in affecting dentists' willingness to treat HIV/AIDS patients.

In a previous paper ${ }^{6}$ the author has presented results from a study of dentists' conducted in the North West of England and funded by South Cheshire Health Authority. The Health Authority felt there was a need for this research because anecdotal evidence within an influential charity HIV/ AIDS organisation in the region suggested

\footnotetext{
1*Professor, Liverpool John Moore's University, Faculty of Health and Applied Social Studies, Josephine Butler House, Myrtle Street, Liverpool L1 7DN

${ }^{*}$ Correspondence to: Prof. Michele L. Crossley

Email:M.Crossley@livjm.ac.uk
}

\section{Refereed Paper}

doi:10.1038/sj.bdj.4811412

Received 15.01.03; Accepted 12.08.03

๑ British Dental Journal 2004; 197: 21-26 that some HIV positive individuals had been experiencing difficulties accessing NHS dental care. As with all studies conducted in this area, this previous study was primarily quantitative, using measures of dentists' knowledge, attitudes and practices towards patients carrying blood-borne viruses such as HIV infection, Hep. B and Hep. C, in order to identify potential barriers to the provision of adequate dental treatment. Although some useful findings were obtained in that study, it was suggested that further qualitative work needed to be conducted in order to explore the findings from the dental practitioners' perspective in more detail. No previous studies have adopted such an approach in relation to these issues. Accordingly, this paper reports the results of such a qualitative investigation.

\section{THE RESEARCH}

During the process of conducting a survey of all dental practitioners in the South Cheshire region (330 in all), dentists were asked to write down their name, address and contact number if they were willing to be interviewed further about the issues addressed in the survey. Fifty-one dentists did so. A random selection of 15 of those dentists were chosen in order to take part in a more detailed semi-structured interview.
This was considered an appropriate number because the aim of the study was to provide an in-depth qualitative exploration of the data and smaller numbers are necessary to achieve this. Ten of those interviewed were men, five women. Twelve worked in a general dental practice setting, while two worked in the community dental service and one worked in a hospital setting. Twelve had worked in dental practice for over 17 years, while three had done so for less than 17 years. All interviewees were white.

The interview was 'theoretically based' insofar as it was designed to clarify and elaborate further on factors that had also been identified in previous studies as potentially impacting on dentists' attitudes and treatment practices regarding HIV+ and patients with other blood-borne viruses. ${ }^{6}$ For instance, one such factor was the dentists' sense of ethical responsibility towards the provision of treatment for various 'high risk' groups. Also important were attitudes towards 'high risk' groups and various concerns relating to the acceptance of HIV/ AIDS patients (potential barriers to providing dental care to HIV/AIDS patients) such as worries about staff concerns, fears of personal risk, financial implications and loss of other patients. During the course of the interviews, dentists were asked to 


\section{PRACTICE}

reflect further on these issues and the findings of the survey. The following section presents the findings obtained as a result of this process of reflection.

\section{FINDINGS}

(NB: All numbers in brackets appearing after quotes refer to the identification number used in the original survey).

\section{Reflecting on ethical responsibility}

The opening question in the semi-structured interviews asked dentists to clarify and elaborate on why they had given a particular answer with regard to a question relating to ethical responsibility. Previous studies have shown that a sense of ethical responsibility is important because it is one of the strongest predictors of refusal or unwillingness to treat HIV/ AIDS patients. ${ }^{7}$ For instance, in the McCarthy et al. (1999) study, it was found that respondents who did not have a sense of ethical responsibility were nine times more likely to report that they would refuse to treat HIV infected patients than respondents who believed they did have such an ethical responsibility

Sixty-six per cent of dentists surveyed in the author's South Cheshire study 'agreed' with the statement: 'As a dentist, I have an ethical responsibility to provide dental care to a HIV+ person'. In the interviews, dentists who answered in this way were asked to elaborate further on why they believed this. Their responses were mainly that, because of their professional ability to treat, they had an obligation to provide such treatment (provided they could do so safely), regardless of the nature of patient or type of illness. For instance, the following comments were typical of those who agreed they had a sense of ethical responsibility to provide treatment to 'high risk' groups such as HIV+ individuals:

\section{In agreement:}

'If a person needs dental care, you're a qualified dentists, and you're able to provide treatment, then you are responsible to provide it, providing it doesn't put you at risk and I don't see that HIV does do that.' (26)

'I think if a patient comes in as an emergency etc., you have to take the patient - because I'm qualified, I can't discriminate against a patient due to a certain disease...' (50)

'...it is our responsibility to treat all patients if we have the ability and equipment to do so. We are health professionals and as such are duty bound to provide care for all.' (63)

'Ethically, as a profession, we can't pick and choose on the basis of an illness they've got no control over anyway.' (37)

There were also more practical considerations. For instance, one dentist said that he felt very strongly about "not stigmatising' patients, not least because if we 'don't offer care we're walking into a minefield they just will start not to tell us at all.' (37)

\section{Undecided:}

Fifteen per cent of dentists in the survey reported that they were 'undecided' as to whether they had an ethical responsibility to provide such treatment. When asked to elaborate on his response, one interviewee said that although "we have a duty as a profession to provide treatment,' he did not think general dental practice was the best setting for this. (40) This, he claimed, was because of the 'disproportionate time involvement' involved in treating HIV/ AIDS patients. He continued:

'...yes, routine IC procedures should be sufficient but I would say extra precautions are needed (eg double gloving) - at the end of the day, accidents can happen in the best of systems. The NHS don't provide for this. We can't do everything. It's just the same as with other patients, for instance, patients with chronic anxiety who we refer for sedation - I mean I could sit them in the chair and give them psychotherapy but I don't I refer them.' (40)

Another dentist also referred to this issue of lack of additional fees on the NHS for the 'extra precautions' that he knew were not 'strictly necessary,' but nevertheless, he 'wanted to take,' when treating HIV/AIDS patients. (68) He also did not feel that a health professional should be forced to treat particular kinds of patients, not least because if they felt uncomfortable doing so, their performance could be adversely affected. But more fundamentally, he believed that:

'...we are entitled to treat who we want, just as a patient is entitled to attend who they want... I think it is an entitlement of a professional person... I think it should be a matter of choice. I've got a problem with this question, it's a question of my freedom.' (68)

\section{Disagreement:}

Nineteen per cent of survey respondents disagreed with the idea that they had an ethical responsibility to treat a HIV+ patient. In the interviews, one female dentist made clear that this was because she believed treatment for HIV+ patients, like hemophiliac patients, should be provided in specialist centres. She commented as follows:

I am not at all averse to providing treatment myself, it's just that I think the best care would be available in such centres. And I wouldn't mind working in such a centre myself. But I think, just in terms of, for their own thoroughness and for patients coming in afterwards as well, it would be best all round. Unless, of course, they felt alienated by referral - in which case they would have to be treated in the surgery.' (136)

Other dentists disagreed however, because of the perceived risks HIV+ patients posed to themselves and their staff, and the conflict between personal and professional duties that this imposed on them. For instance, although one dentist believed that "we have a professional responsibility (not necessarily ethical)' to make sure treatment is available, he did not think he should have to provide that care personally. He reiterated:

'It's our responsibility to make sure that there is care available - but it's also my personal responsibility to put myself and my family first - your professional responsibility does not override personal responsibility. I had a friend who treated a drug addict and he actually died from a needlestick - I think that's beyond all professional duty.' (137)

\section{Another dentist also felt if:}

'... we felt any compromise to our own health, then we are always entitled to decline or refer elsewhere - if that's appropriate. In most circumstances we would treat, but you always have the right to decline treatment.' (114)

And finally, another dentist felt that HIV+ patients should be referred to the CDS and not be treated in the GDP surgery. 'The reason I feel so strongly about this,' he continued, was that:

'...comparing HIV with Hep. B, while it's easier to catch Hep. B, we have immunisation against it, so, not just for me, but also for my staff, the girls, feel very strongly about it. If you get HIV there are problems with insurance, problems with work, and consequently, I think we do have an ethical responsibility to ensure they receive treatment, but where people have got the time and facilities to treat.' (96)

Differences in type of dental practice and perception of ethical responsibility

One of the findings of the survey was that GDPs, when compared with dentists working 
in 'other' settings (such as hospitals and the CDS), were significantly less likely to exhibit a sense of ethical responsibility (58\% compared with $\left.91 \%, \chi^{2}=13 \mathrm{df}=2, P<0.001\right) .{ }^{6}$ In the interviews, dentists were asked to reflect on why they thought this might be the case. Their reasons basically came down to time and money. One dentist working in the CDS commented that "we know by the time they've got to us they've got to the end of the line'. But she also recognised that 'at the end of the day, we're not running our own business so we don't have to worry about what other patients think.' (26)

GDPs repeatedly emphasised that 'financial imperatives' and the fact that they were running businesses made ethical imperatives seem entirely theoretical. One private dentist recognised that, although he was in private practice, in the NHS there is 'barely any NHS recompense for time and for adequate cross infection. The NHS fee scales are just a joke on these matters.' (76) Another dentist recognised that there are 'lots more in the way of social issues, lots of other issues, it's not just about teeth.' All of this often resulted in poor attendance and cancelled appointments which all took time and resulted in reduced profits. This was also why, one dentist commented, if 'there's no financial incentives people will steer away because it just takes longer to treat.' (37) Another commented:

'To some extent it is business that comes into it - one is running a business and although in theory the same IC procedures should be followed for everybody, in practice the NHS 'promotes' a system of corner cutting - its financial structure means that any patient that takes longer, for instance, the same would apply to a nervous patient, it slows the whole process down and means that the patient is unprofitable to see. In a business setting you can't see many people who are unprofitable. I mean, you don't see Marks and Spencers giving away clothes do you?' (133)

Finally, another dentist reiterated these issues in the following quote:

'GDPs are less educated, but they're also more constrained financially - especially if you're working with the NHS you've got failed appointments, lab bills that cost more than the fee... You can accept treating some patients without profit but you can't treat every patient. You can accept one financial penalty - I mean, if you treat a handicapped person in the morning this may obliterate any profit in one morning, so you can't treat another handicapped patient in the afternoon. You just can't do it. You can't treat a lot of patients who are not going to be cost-effec-

Table 1 Percentage of survey respondents' attitudes towards treating various 'at risk' groups. ${ }^{6}$

\begin{tabular}{lccc}
\hline How would you feel about treating: & $\begin{array}{c}\text { 'No } \\
\text { hesitation' } \\
(\%)\end{array}$ & $\begin{array}{c}\text { 'Accept with } \\
\text { some hesitation' } \\
(\%)\end{array}$ & $\begin{array}{c}\text { 'Refer } \\
\text { patient elsewhere' } \\
(\%)\end{array}$ \\
\hline A homosexual/bisexual man & 87 & 11 & 2 \\
\hline A hemophiliac & 69 & 16 & 15 \\
\hline A patient infected with Hep. B virus & 48 & 43 & 9 \\
\hline An IV drug user & 52 & 35 & 21 \\
\hline A patient infected with Hep. C virus & 39 & 38 & 20 \\
\hline A patient diagnosed with HIV/AIDS & 45 & 35 & 1
\end{tabular}

tive, for want of a better word. This sounds awful talking about people like this but it's the reality.' (136)

\section{Gender differences in perception of ethical responsibility}

With regard to one of the statements assessing ethical responsibility ('health professionals should have the right to refuse to provide treatment for a $\mathrm{HIV}+$ person), female dentists were far more likely to agree than male dentists (63\% compared with $\left.31 \%, \chi^{2}=14.7, \mathrm{df}=2, P<0.0001\right) .{ }^{6}$ In interviews, dentists were asked to reflect upon why they thought this might be the case. A few suggested that perhaps women are just 'more caring' than men $(23,40)$. One female dentist recognised that 'although it's a sweeping generalisation,' in her experience '...female dentists are more ethically and morally oriented than men.' (76) Another community dentist said that she did not see many male dentists in the community because most were female. Perhaps, she reflected, "because of the history of HIV disease,' men would be 'more likely to have negative attitudes towards it due to it being mainly in the gay community.' (26)

But there was also a recognition that gender differences emerged, not from intrinsic gender differences, but due to differences in status in the profession. The same female dentist who said she thought female dentists were more ethically/morally oriented, "more compassionate rather then 'churning volume $=€$,' and 'men are more money driven,' also recognised that this depended on the professional status of the dentist - whether they were salaried as vocational trainers (VTs) or associates. As soon as they become associates, she said, they start to 'churn out - it's just a mindset.' (76) Another dentist reiterated this when he commented that:

'It depends how politically incorrect you want me to be. If you look at the breakdown of GD principals, the majority are males and if I were to consider this question economically - treating these patients on the NHS - you can't do it. So males - there are less females as principals, so they don't have the same financial imperative - I think that would be why males would be more reticent.' (37)

Likewise, another female dentist who had been a principal up until the previous year made the following comments:

'Men are horrible (laughs). No, seriously, I suspect it has a lot more to do with more men being principals - I mean, I was a principal until last year. You seemed surprised when I said I would give the nurse the option to treat and that I would be as concerned about her as the patient. But, I think men think more commercially than ladies and you potentially could have tribunal concerns on your hands with nurses even if you explain everything - HIV has such a psychological aura about it - if they genuinely do go home and have sleepless nights... Men are less emotional, and at the end of the day, HIV+ patient take too much time to treat therefore it is not financially worth it - it's like the handicapped. This all sounds awful but it's the reality.' (136)

\section{ATTITUDES TOWARDS 'AT RISK' GROUPS}

The results from the survey showed that a considerable degree of dentists expressed reservations about treating patients with various different types of blood-borne viruses (see Table 1).

During interviews, dentists were asked to explain further why they felt hesitant in relation to various groups. Different reasons were given in relation to different groups of patients. For instance:

\section{Hemophiliacs}

This was mainly due to ensuring specialist treatment for the condition was available. A number of dentists did not feel they knew enough about hemophilia and the complications of treatment, post-operative complications, and the risks of infection for hemophiliac patients themselves. $(24,40,50)$

\section{IV drug users}

IV drug users were seen generally per- 
ceived as 'high risk' people. 'We do know some of our patients who are drug users who have been loyal patients,' said one dentist, 'but it's not a niche market that we want to expand into...' (40) 'They're usually poor attenders - dreadful,' (136) commented another.

\section{Hepatitis C}

A number of dentists were wary about Hep. C patients because there is "no immunisation against it.' (76) One dentist did not think that the risks of Hep. C were fully understood:

'I understand the transmission risks for HIV (low) and Hep. B (low, because we've got vaccination). But Hep. C is a bit more of a problem area.' (133)

Another dentist reported having had a bad experience when he was doing his vocational training.

'I stuck my finger with a needle and it took 6 months to get a response from the lab. - it was a very difficult time for me very traumatic.' (50)

\section{HIV/AIDS}

Amongst those who were hesitant about treating HIV/AIDS patients, this was largely due, as with hemophiliacs, to the perception that the best treatment could be provided in specialist centres. 'It's much like leukaemic patients,' said one dentist, 'we tend to become unaware when treatment protocols change - we see so few of these patients.' (136) There was also a perception, however, that HIV/AIDS patients, like IV drug users, were typically unreliable and tended to cancel appointments. As one dentist made clear:

'I'm happy treating HIV+ patients, well, it depends on the nature of the patient - as long as they come and have treatment, we're a private practice but we have a VT who sees NHS patients and classically, there's a lot more failed appointments and time wasting, due to social issues - but if they're fine... (136)

Another dentist, however, did make clear that he was hesitant about treating HIV/AIDS and other 'handicapped' groups because they often posed problems in terms of their demands which, to him, seemed unjustifiable:

'Basically, there's an element of risk that I don't think you can eliminate - so there has to be a decision point when you say yes/no. It can't be carte blanche. There's also other problems. A lot of these patients want to be treated as 'normal' patients - otherwise they feel discriminated against. But each patients is treated as an individual in this surgery. Eg if a patient in a wheelchair comes for treatment, my surgery is upstairs, so I have to make a special time available to treat downstairs - but wheelchair users then feel that they are being discriminated against. I feel that patients have to fit in with my practice - they have to be discriminated against eg if a patient has complicated treatment I'll put them at the end of a session - it's the same for everyone. But HIV/drug users/wheelchair users mind about that - they think they're being discriminated against - which they are, but so is everyone because everyone has individual treatment needs.' (137)

\section{Homosexual/bisexual men}

Some of the dentists interviewed had previously responded that they would have some hesitation in treating homosexual/ bisexual patients. When asked to elaborate on his reasoning, one dentist said that they constituted a 'high risk' group:

'...going back years ago, all the AIDS scare, they reckoned we would be inundated with patients with AIDS in the general population - this hasn't happened - it's confined to gay men/drug addicts therefore they are higher risk categories.' (96)

A number of other dentists admitted that their hesitancy was based on 'a gut feeling rather than any logical reason.' (133) One dentist, initially surprised that she had responded on the survey that she would be hesitant in treating such patients, then went on to admit:

'I suppose, in truth, I'm probably a little more cautious with gay men, I would probably dispose of the matrix band, for no good scientific reason - I would be slightly more aware. I would probably adjust slightly. I would dispose of things that I would otherwise recycle - more in terms of the potential risks to other patients than anything else.' (136)

No hesitation with any of the patient groups Some dentists responded that they would not have any hesitation in treating any of the 'at risk' groups. Two of the dentists interviewed fell into this category. One dentist claimed that this was because, as a community dentist, it 'is a role I am expected to fulfil.' (26) Another claimed that 'if we are properly trained and equipped, have the correct procedures in place, there is no problem treating such patients.' (63) When asked why he thought other dentists may express hesitation in relation to various groups of 'at risk' patients he commented as follows:
'I would say it is probably fear of the unknown. There is still a view that patients should be referred and let someone else treat them. I don't know why. I see no great difference in treating these patients to treating those with other medical conditions - we take a good medical history, investigate anything that is important and take the necessary action prior to treatment to ensure good quality dentistry delivered safely for the patient and safely for ourselves, staff and other patients.' (63)

\section{PERCEIVED BARRIERS TO ACCEPTING HIV/AIDS PATIENTS}

Following on from other previous studies, respondents in the survey were asked about a number of potential concerns relating to the treatment of HIV/AIDS patients. These concerns included: loss of other patients from the practice; dealing with staff fears about patients with HIV/AIDS; increase in personal risk due to treating patients with HIV/AIDS; and, financial burden for the practice due to increased infection control procedures. During interviews, respondents were asked to elaborate further on their worries and concerns. Each of these concerns is addressed in more detail below.

\section{Dealing with staff fears}

The greatest fear of respondents related to dealing with staff fears, with 59\% of respondents expressing concern in relation to this issue. ${ }^{6}$ A number of dentists were worried about the fears of nursing staff who worked in the surgery. This frequently related to the problems of nurses refusing to work 'chair-side' when treating a HIV+ patient. One dentist recounted the following story in this vein:

'Yes, at the time I was filling in the questionnaire one of the ladies who works here, she's personal assistant to the dental services manager but she's also a dental nurse and she also works for the BD Nursing Association - she was telling me that she'd received a phone call from a dental nurse in who was upset because a Hep. B patient had just been taken on in the surgery, and the dentist had said to her that she had to work chair-side, so she wanted some advice on this. And the advice basically was, no, you can't refuse - there's no reason why you should. But that got me thinking, I suppose if you've got nurses who aren't yet qualified etc. they might get a bit scared. Although my nurses here are all very well informed so I don't think I'd have a problem, but I guess you could have problems...' (24)

A number of dentists were concerned, especially about younger staff, some of whom came ‘straight from school' and got 
'quite scared and worried' when they had never 'been with a HIV/AIDS patient before.' (37) 'One or two of the girls were pregnant last year and I had concerns with Hep. C patients, it's bad enough when it's the girls themselves but when they've got a passenger on board,' said one dentist. (37) 'If a person has an infectious disease some people get very anxious - they're scared of getting infected by the patient.' (50) One dentist said that:

'Everybody is concerned with every risk these days, people ask about amalgams, about cross infection, X-Rays etc. And a lot of the staff here are middle aged family ladies who take things very seriously and question things - when they're explained, they take a logical rather than emotional view, but these things would need to be addressed.' (133)

Some dentists felt that staff fears could be appropriately dealt with by education. One dentist claimed that: 'I would certainly be aware of any misgivings my staff had and would discuss these problems with them and try and allay their fears.' (63) Good communication and keeping staff fully informed, properly trained and well disciplined in cross-infection controls would help. (63) But others were more concerned about the 'emotive' and 'irrational' response to risk. For instance, the following comments illustrates such concerns:

'Fear isn't rational. It doesn't relate to risk. If people are afraid, as an employer it is my responsibility to make sure people feel safe. Accidents can happen, we're not immunised against HIV, there is no immunisation...' (40)

Another dentists was concerned that, even with appropriate education, staff may remain extremely anxious:

'What do I do? I've got someone in the practice who is extremely anxious about dealing with one of the patients - even after exploring safety issues etc. I'm not in a position, if staff refused to help. I don't believe I could take any disciplinary procedure, well I probably could but I wouldn't and I don't think I should. I mean, I haven't done it before because I've never had any HIV/AIDS patients, but should I start to ask prospective candidates in this practice whether they're willing to work with such patients?' (68)

And another dentist expressed similar concerns:

'How do you take responsibility for how your employee is going to feel - I can't do that - so the fact that I take responsibility for clinical care etc. - I can't take responsibility for how my staff would react - we try to explain everything but that doesn't alter the fact that they might have a prejudice how do you square that?' (137)

A number of respondents also reported that although they 'rationally' knew that routine IC procedures should be adequate to deal with HIV positive patients, nevertheless, if they were knowingly treating such patients, staff would want to take additional precautions, 'more along the lines of Hep. B.' For example:

'... at the end of the session, surfaces disinfected, go for it all if the occasion arose. Yes, IC procedures should be adequate but when you know of an additional risk (eg from aerosols), you want to take additional precautions. I'd be happier probably obviously this is probably personal rather than logical.' (114)

In a similar vein, another dentist reported that:

'Yes, it's the same old story - if someone comes in and they've got a problem you don't know about, you're relying on normal procedures - if someone comes in and you do know, you're not supposed to, but you do. That's just being doubly careful. The way thinking is, that shouldn't be necessary, you're criticised for taking extra precautions but... (137)

\section{And yet another:}

'Sure, there's the argument that routine IC procedures should be sufficient but I would want to do more - it's probably fear on my part but there's that additional anxiety. It's a fatal disease - probably patient to patient cross infection would be less of a worry than patient-dentist. I mean, you can prick your finger or anything. I'm just trying to be honest. You know, I drop my speed when I drive in the rain...' (40)

\section{Personal risk}

Thirty-six of dentists surveyed were concerned about the personal risk posed to them by treating HIV infection. In a number of cases this fear derived from either having read articles about needlestick injuries, as in the following quote:

'... there was an article/ letter to the $B D J$ 4/5 years ago, a guy with a needlestick injury - it takes so long with blood tests - for 12 months his life was a nightmare. I don't want to go through that personally.' (96)

Or, from previous personal experi- ence, as recounting in the following anecdote:

'I treated a lad a couple of years ago, I must have been stupid. I did an apicectomy so there was obviously lots of blood about, and I prescribed Pethadine, and then the pharmacist phoned me, and said, you do know he's an addict don't you. And for some reason, it had just not crossed my mind. And then I got really worried. Because I couldn't remember having stabbed myself or anything during the procedure, but it does happen, you know, every couple of weeks you do things like that, but the problem was, I couldn't remember what had happened during the apicectomy. I had several sleepless nights because I couldn't remember what had happened. I would have been doubly cautious if I had been aware, but because I didn't know, I hadn't been. Well, I just couldn't remember what I had done in the procedure. I phoned the doctor and he wouldn't tell me whether the lad was HIV+ - which I thought was wrong - I felt I had a right to know. And then there was another case last year when I had a pregnant associate. She caught herself on the trolley - on the slow hand piece burand at the time, we were treating a young lad who was married with a baby, but he wasn't working etc. Anyway, she was demented that she would get HIV - I mean, there was very little chance of him being HIV, but nevertheless, her fears were very genuine.' (136)

Another dentist reported that although he had been on a HIV awareness course which had changed his attitudes 'quite a lot', he still had 'mixed feelings' and remained fearful:

'... but what continues to worry me - if you thought you had a needlestick injury from Hep. B/ HIV - the regime you had to go through was horrendous - that scared me - the drug regime. I mean, in the old days, you'd just have a dose of penicillin, but that's why I wouldn't want to put myself at risk...' (137)

\section{Loss of other patients}

Thirty-four per cent of dentists surveyed reported concerns with regards to potential loss of other patients from the practice. This related to lack of knowledge about the 'general public's' attitudes towards HIV/ AIDS. 'People have fears about contagious diseases - there's no cure for HIV - people die, people might perceive that they were at increased risk,' (40) said one dentist. Another said that he was 'not quite sure how the public at large view these issues - if we were to see a lot of these patient - I don't know what 
the public's thoughts would be and that would concern me.' (133)

And another:

'Well, if patients in my practice found out I was treating even a small number they would be unhappy - about following them into the surgery - it's a fact of life, the world we live in - so anyone who answers that they're not bothered are not in the practice. You make commercial decisions as well as moral decisions. If you're in a hospital setting you don't give a bugger whether the patients come back or not... it's totally different if you're trying to run a business.' (68)

\section{Financial implications}

Thirty-two per cent of dentists reported concern with regard to the financial implications for their practice if they were to accept HIV/AIDS patients. Basically, this related to the 'disproportionate amounts of time to provide appropriate care' that would be involved with such patients. This opinion is typically represented in the following quote:

'As a busy practitioner, I can absorb a number of HIV/ Hep. C patients but there is a limit. I think even though basic IC procedures are adequate, additional precautions still need to be taken - especially with Hep. $B$ and C. In a hospital setting, I remember those halcyon days, you don't even have to think about things like that. I mean, for example, say I was to take out an upper 6 in a Hep. C positive patient - the fee on the NHS is just under $£ 10$ - it doesn't even allow for the clinical time to clean up etc. It's just not viable...' (37)

'I work in private practice so it's not a problem for me,' said another dentist, 'but if I was working on the NHS I would be very worried.' (37) 'The additional costs involved in treatment just aren't reimbursed,' (96) was the conclusion of another dentist.

\section{ANY ADDITIONAL COMMENTS?}

During the interviews, dentists were asked if they had any additional com- ments that they would like to air in relation to the issues covered in the questionnaire and interview. One of the dentists felt that there was not enough information around about specialist centres in which 'full blown AIDS patients' could be treated - 'so circulating knowledge of such centres would be useful.' (114) Most comments, however, related to the fact that the extra time and effort taken to treat HIV positive patients remained inadequately renumerated on the NHS fee scales:

'There's a big financial issue if you survey GDPs - it's the extra time - these high risk patients are very high in resources.' (76)

In relation to this point one dentist made the following comment:

'I've never quite understood the stance of the BDA or the DoH on IC guidelines on HIV patients. I know what they are but I don't understand the philosophy. If you get someone with HIV, like Hep. C you need to take additional IC procedures. With my Hep. B patient, I use cling film, everything is bagged up, gloves, mask, see him at the end of the day. If the BDA are saying that our routine procedures should be adequate - I wouldn't be happy with that. I would want to do all of the additional IC procedures as with Hep. B - but in a routine GP setting, you can't do that - you just don't have the time.' (96) that:

Likewise, another dentist commented

'I feel the system expects rather than encourages too many patients to be treated in not enough time. Hence, the perturbance about dealing with these people in the best possible way for all concerned.' (133)

In the final instance, one dentist concluded, there 'needs to be set aside funding for GDPs to treat such patients.' Most of the 'resistance from intelligent people to treating these patients is due to financial reasons - at the end of the day, we're running businesses...' (37)

\section{CONCLUSION}

This paper has attempted to draw out in more detail dental practitioners' beliefs and opinions with regard to the treatment of HIV+ and other patients with bloodborne virsues. The aim of such interviews is not to provide a representative sample of dental practitioners, but to explore in more detail some of the findings reported on the basis of a previous survey. All of the available literature in this field is based on quantitative studies which provide the dental practitioner with no room to expand, reflect upon, and justify his/her beliefs or opinions with regard to the treatment of HIV+ patients and other 'high risk' patients. This preliminary study aimed to rectify this deficit and to provide dental practitioners with the opportunity to put forward their opinions in more detail. As can clearly be seen the findings presented in this study have important implications for the treatment of HIV+ individuals within the context of NHS dentistry.

1. Quartey J. Impact of HIV on the practice of dentistry in Houston, Texas. Texas Dent J 1998; November issue, pp45-57.

2. McCarthy M, Koval J, MacDonald J. Factors associated with refusal to treat HIV infected patients: The results of a national survey of dentists in Canada. Am J Public Health 1999; 89: 541-545.

3. Craven $\mathrm{R}, \mathrm{O}$ 'Brien $\mathrm{K}$, Bennett $\mathrm{E}$. Impact on English dentists of the threat of HIV infection. Community Dental Oral Epidimiol 1996; 24: 228-229.

4. Kunzel C, Sadowsky D. Comparing dentists' attitudes and knowledge concerning AIDS: differences and similarities by locale. J Am Dent Assoc 1991; 122: 55-61.

5. Gerbert B. The impact of AIDS and dental practice: Update 1989. J Dent Educ 1989; 53: 529-530.

6. Crossley M. L. An investigation of dentists knowledge, attitude and practices towards HIV+ and patients with other blood borne viruses in South Cheshire, UK. Br Dent J 2004; 196: 749-754.

7. McCarthy M, Koval J, MacDonald J. (1999). Factors associated with refusal to treat HIV infected patients: The results of a national survey of dentists in Canada. Am J Public Health 1999; 89: 541-545. 